\title{
DENTAL NURSES INVITED TO A STUDY DAY ON LATEST OMFS CLINICAL PRACTICE
}

British Association of Oral and Maxillofacial Surgeons (BAOMS) President Austen Smith has put out a call to dental nurses to join the surgeons at their 2021 Sheffield Annual Scientific Conference (ASM) for the first ever study day for nursing colleagues. There is also a day of separate sessions for maxillofacial prosthetists and technologists (IMPT - Institute of Maxillofacial Prosthetists and Technologists).

Austen Smith said: 'I've asked BAOMS members to talk to our OMFS and dental nursing colleagues who work with us in theatres, clinics and wards to let them know there's a dedicated programme for them at the BAOMS ASM - and we'd love to see them here in Sheffield'.

The OMFS Nurses' Study Day programme is fully integrated with the BAOMS ASM at the University of Sheffield Diamond Centre on 9 Saturday October

\section{I ANNUAL SCIENTIFIC MEETING SHEFFIELD}

SATURDAY 9 OCTOBER 202I

LECTURETHEATRE 4 (LT4), DIAMOND CENTRE, UNIVERSITY OF SHEFFIELD

\section{OMFS NURSES DAY}

AT THE BAOMS ANNUAL SCIENTIFIC MEETING, UNIVERSITY OF SHEFFIELD

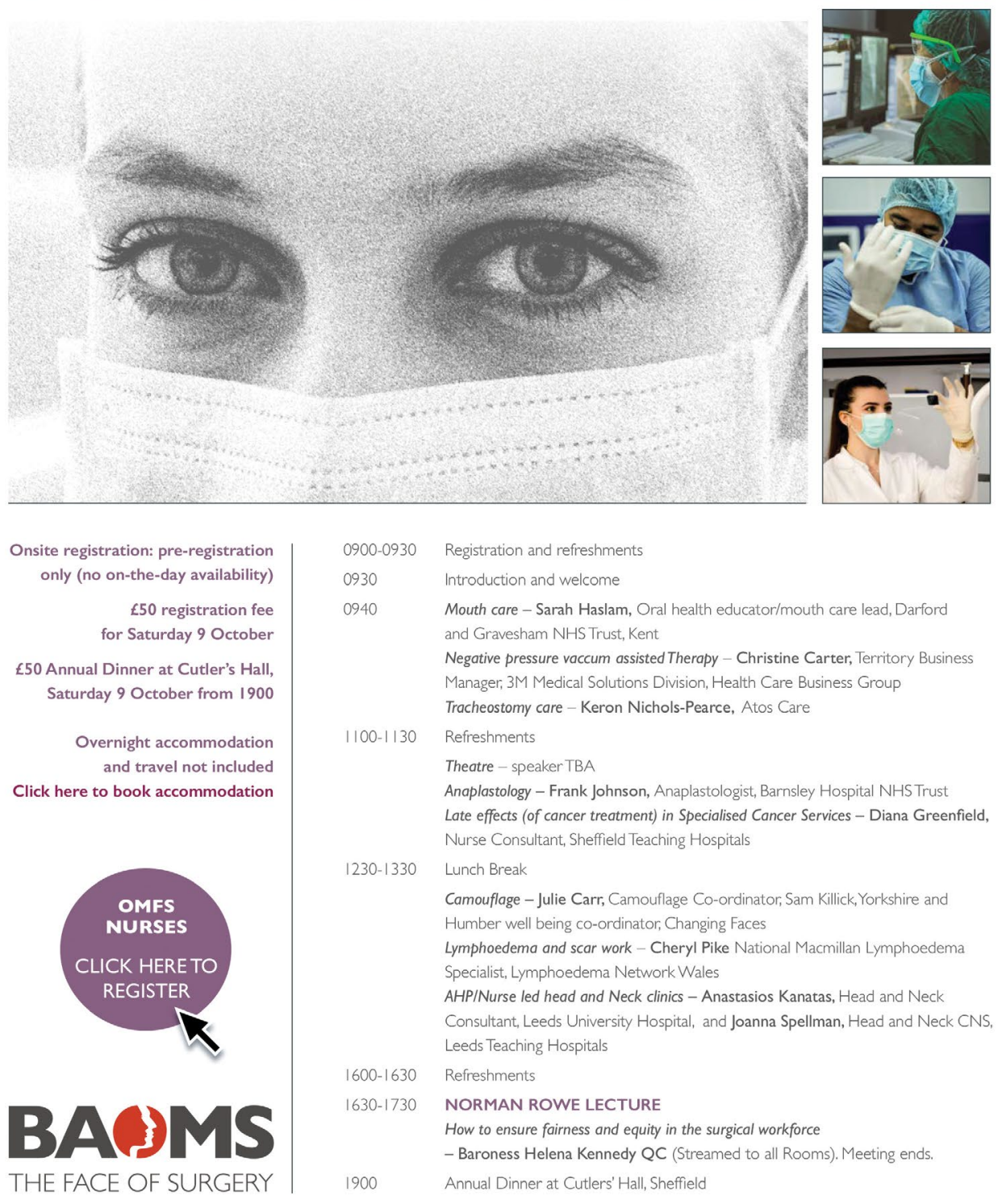

2021 with sessions on the latest OMFS nursing care and development in wards, theatres and clinics. The programme includes current practice on mouth care presented by Sarah Haslam, the Oral Health Educator/Mouth Care Lead for Dartford and Gravesham NHS Trust, and a session on allied health professions/ nurse-led head and neck $(\mathrm{H} \& \mathrm{~N})$ clinics led by $\mathrm{H} \& \mathrm{~N}$ Clinical Nurse Specialist Joanna Spellman together with H\&N Consultant Anastasios Kanatas, from Leeds Teaching Hospitals. BAOMS President Austen Smith's conference theme is 'OMFS How to do it: A workshop manual'. It's made up of two days of sessions with a focus on the basics and a series of how-to guides from oncology and reconstruction, deformity and TMJ and aesthetics, to cleft and craniofacial.

Everyone attending this year's BAOMS ASM must pre-register. To pre-register for the OMFS Nurses' Day at the BAOMS 2021 Sheffield ASM 9 October, Sheffield University Diamond Centre email: office@baoms.org.uk

The BAOMS ASM programme is available at https://baoms 21 . talkingslideshd.com/home. and you can read the full details of the OMFS Nurses' Day study day on page 7 .

Organisers: British Association of Oral and Maxillofacial Surgeons: office@baoms.org.uk 